\title{
Superficial properties of Ti6AI4V discs obtained by the additive and subtractive manufacturing method
}

\section{BASIC RESEARCH \\ Biomaterials, Material \\ Sciences, Implants}

\author{
Valente MLC, ${ }^{1}$ de Oliveira TT, ${ }^{1}$ Kreve S, ${ }^{1}$ Lisboa RB, ${ }^{2}$ Pauly $S,{ }^{3}$ \\ Bolfarini $\mathrm{C}^{2}$ dos Reis $\mathrm{AC}^{1}$
}

1 Department of Dental Materials and Prosthesis, School of Dentistry of Ribeirão Preto, University of São Paulo, Brazil 2 Department of Materials Engineering, Federal University of São Carlos (UFSCar), Brazil

3 Institute for Complex Materials, Leibniz Institute for Solid State and Materials Research (IFW), Germany

\section{Abstract}

Selective Laser Melting (SLM) is a recent additive manufacturing (MA) technique that can be employed in custom implant making. The aim of this study was to evaluate and compare the physico-chemical and mechanical properties of Ti-6Al-4V discs obtained by the additive manufacturing (SLM), and subtractive manufacturing by conventional machining. Were used 30 discs $(n=10)$, divided into 3 groups: additive manufacture by SLM (DSLM); conventionally machined with surface treatment $\mathrm{H}_{3} \mathrm{PO}_{4}+\mathrm{NaOH}$ (DCMST), and conventionally machined without surface treatment (DCM). In order to characterize the surfaces, Scanning Electron Microscopy (SEM), X-ray Dispersive Energy Spectroscopy (EDS), surface roughness by confocal laser microscopy and wettability by a goniometer were performed. ANOVA and Tukey's test $(\alpha=0.05)$ were used for the quantitative analysis. MEV images showed a rougher surface of the DSLM, with unfused spherical particles, the DCMST topography similar to a sponge or coral, characteristic of applied nanometric treatment and DCM, polished surface. EDS demonstrated the presence of the essential elements of the alloy ( $\mathrm{Ti}, \mathrm{Al}$ and $\mathrm{V}$ ) in the $\mathrm{DCM}$ and DSLM, in the DCMST also showed the presence of $\mathrm{Na}$. For the roughness parameters ( $\mathrm{Ra}$ and $\mathrm{Sa}$ ), DCMST $(0.17$ and $0.18 \mu \mathrm{m})$ and $\mathrm{DCM}(0.06$ and $0.07 \mu \mathrm{m})$ were similar $(p=0.974)$, the highest mean was observed for DSLM $(9.09$ and $11.03 \mu \mathrm{m})(\mathrm{p}<0.001)$. For wettability, the DCMST had the less contact angle $\left(18.55^{\circ}\right)$ and the DSLM had the highest $\left(103.23^{\circ}\right)(p<0.001)$. In the present study, the MA promoting greater roughness and less hydrophilicity in DSLM discs. Thus, further studies should be performed to ensure the effectiveness of this technique in dentistry.

\section{Background and Aim}

Rapid prototyping, also known as additive manufacturing (MA) or $3 \mathrm{D}$ printing, is a rapidly expanding manufacturing technology with great potential for different medical and dental applications. The technique of selective laser melting (SLM) is the most recent method of MA that can be used in the manufacture of customized dental implants, being the main difference of 3D implants compared to 2D models, the surface. The objective of this study was to evaluate and compare the physico-chemical and mechanical properties of Ti-6Al-4V discs obtained by the additive manufacturing, Selective Laser Melting (SLM), and subtractive manufacturing by conventional machining.

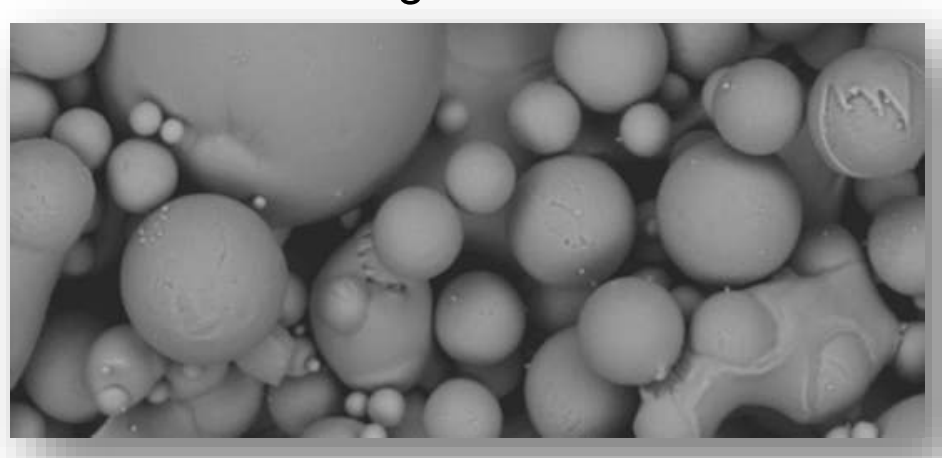

\section{Methods and Materials}

30 discs, divided into 3 groups $(n=10)$ were used: additive manufacture by SLM (DSLM); conventionally machined with surface treatment (DCMST), and conventionally machined without surface treatment (DCM) (Table 1).

Table 1. Characteristics of Ti-6Al-4V discs

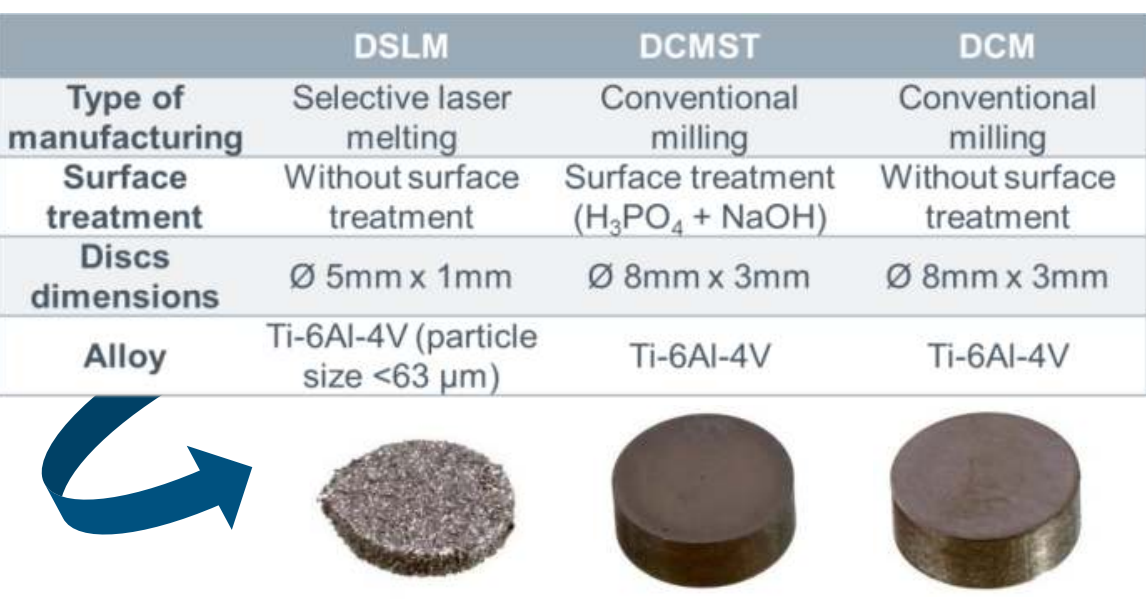

The equipment used for SLM was the REALIZER GmbH SLM 50®) (IFW Dresden Institute, Dresden, Germany) with continuous wave fiber laser $(\lambda=1070 \mathrm{~nm}, \mathrm{~F}$ position: 9.55 $\mathrm{mm}$, spot size $\approx 60 \mu \mathrm{m}$ ) using gas-atomized Ti$6 \mathrm{Al}-4 \mathrm{~V}$ powder with particle size $<63 \mu \mathrm{m}$.

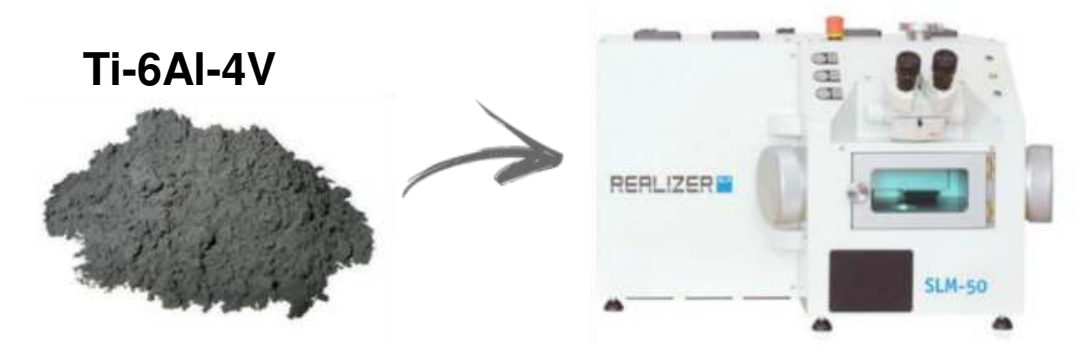

Surface Characterization

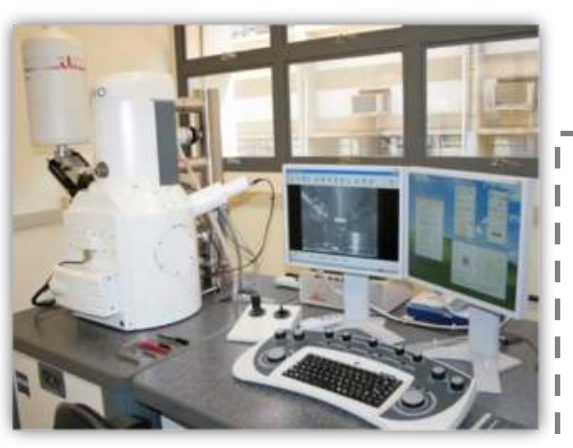

SEM/EDS

Carl Zeiss mod. EVO 50/EDS/ IXRF Systems mod. 500 Digital Processing)

Surface Roughness

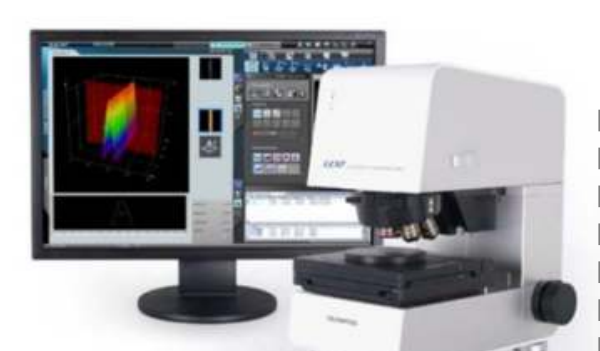

Confocal Microscopy

- Ra/Sa parameters

- Magnification of 20x

Resolution of $1024 \times$ 1024 pixels

(LEXT 4000; Olympus, Hamburgo,

$20 \mathrm{kV}$ acceleration

Objective aperture of $20 \mu \mathrm{m}$

Distance $5 \mathrm{~mm}$ (SEM) and $8.5 \mathrm{~mm}$ (EDS)

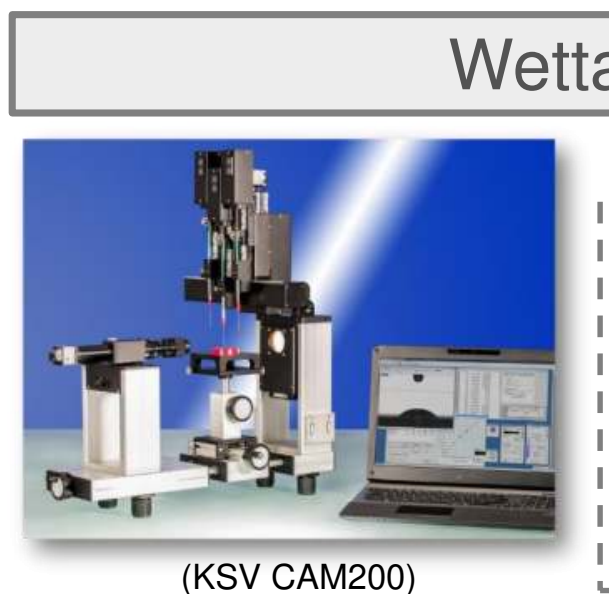

Wettability

\section{Goniometer}

- Drop of 4- $\mathrm{LL}$ distilled water

60 seconds stabilization

- Dried with a 1-min nitrogen flow

ANOVA and Tukey's test $(\alpha=0.05)$ were used.

\section{Results}

MEV images showed a rougher surface of the DSLM, a topography similar to a sponge or coral of the DCMST, and polished surface for DCM.
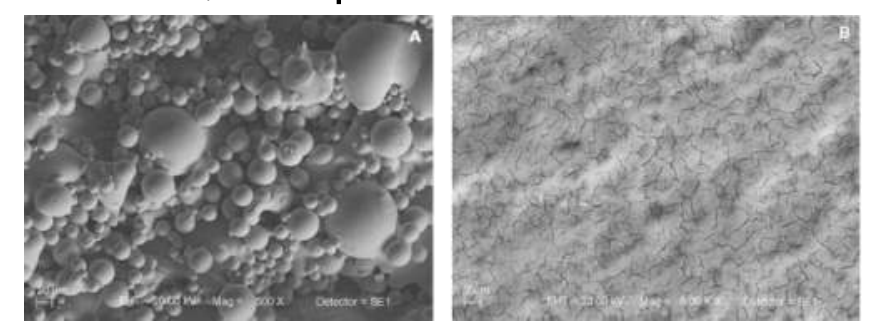

EDS demonstrated the presence of the essential elements of the alloy (Ti, Al and V) in all discs, in the DCMST also showed the presence of $\mathrm{Na}$ (Table 2).

\begin{tabular}{ccccc}
\multicolumn{5}{c}{ Table 2. Chemical composition of Ti-6Al-4V discs } \\
\hline \multicolumn{5}{c}{ Weight percent (wt.\%) } \\
\hline Samples & $\mathrm{Ti}$ & $\mathrm{Al}$ & $\mathrm{V}$ & $\mathrm{Na}$ \\
DSLM & 88.24 & 8.82 & 2.93 & - \\
DCMST & 86.33 & 6.51 & 2.52 & 4.62 \\
DCM & 89.65 & 7.02 & 3.31 & - \\
\hline
\end{tabular}

For the roughness parameters ( $\mathrm{Ra}$ and $\mathrm{Sa}$ ), the highest mean was observed for DSLM (9.09 and $11.03 \mu \mathrm{m})(p<0.001)$; DCMST $(0.17$ and $0.18 \mu \mathrm{m})$ and DCM $(0.06$ and $0.07 \mu \mathrm{m})$ were similar $(p=0.974)$.

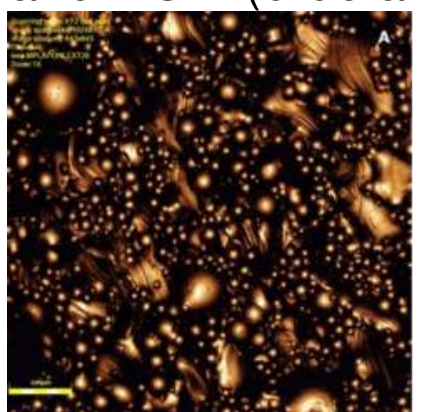

For wettability, DSLM had the highest $\left(103.23^{\circ}\right)$ $(p<0.001)$ contact angle, and the DCMST had the less $\left(18.55^{\circ}\right)$

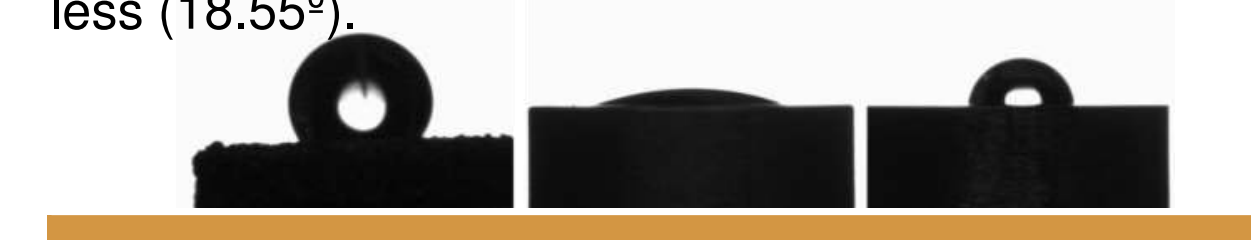

Conclusion

Although MA presents innumerable advantages inherent in the technique, such as the possibility of product customization, waste reduction, energy consumption and duration of surgeries. In the present study, the MA promoting greater roughness and less hydrophilicity in DSLM discs. Thus, further studies should be performed to ensure the effectiveness of this technique in dentistry.

\section{References}

1. Oliveira TT, Reis AC. Fabrication of dental implants by the additive manufacturing method: A systematic review. Prosthet Dent. 2019.

2. Wally ZJ, Haque AM, Feteira A, Claeyssens F, Goodall R, Reilly GC. Selective laser melting processed Ti6Al4V lattices with graded porosities for dental applications. J Mech Behav Biomed Mater. 2019;90:20-29.

3. de Oliveira DP, Toniato TV, Ricci R, Marciano FR, Prokofiev E, Valiev RZ, et al. Biological response of chemically treated surface of the ultrafine-grained Ti-6Al$7 \mathrm{Nb}$ alloy for biomedical applications. Int $\mathrm{J}$ Nanomedicine. 2019;14:1725-1736. 